\title{
Niche acclimatization in Red Sea corals is dependent on flexibility of host-symbiont association
}

\author{
Maren Ziegler ${ }^{1,2,3}$, Cornelia Roder $^{1}$, Claudia Büchel ${ }^{2}$, Christian R. Voolstra ${ }^{1, *}$ \\ ${ }^{1}$ Red Sea Research Center, Division of Biological and Environmental Science and Engineering, \\ King Abdullah University of Science and Technology, 23955-6900 Thuwal, Saudi Arabia \\ ${ }^{2}$ Institute of Molecular Biosciences, Department of Biosciences, Goethe University Frankfurt, Max-von-Laue-Straße 9, \\ 60438 Frankfurt am Main, Germany \\ ${ }^{3}$ Ichthyology Section, Senckenberg Research Institute and Natural History Museum, Senckenberganlage 25 , \\ 60325 Frankfurt am Main, Germany
}

\begin{abstract}
Knowledge of host-symbiont specificity and acclimatization capacity of corals is crucial for understanding implications of environmental change. Whilst some corals have been shown to associate with a number of symbionts that may comprise different physiologies, most corals associate with only one dominant Symbiodinium species at a time. Coral communities in the Red Sea thrive under large fluctuations of environmental conditions, but the degree and mechanisms of coral acclimatization are largely unexplored. Here we investigated the potential for niche acclimatization in 2 dominant corals from the central Red Sea, Pocillopora verrucosa and Porites lutea, in relation to the fidelity of the underlying coral-symbiont association. Repeated sampling over 2 seasons along a cross-shelf and depth gradient revealed a stable symbiont association in $P$. verrucosa and flexible association in $P$. lutea. A statistical biological-environmental matching routine revealed that the high plasticity of photophysiology and photopigments in the stable Symbiodinium microadriaticum (type A1) community in $P$. verrucosa were correlated with environmental influences along spatio-temporal dimensions. In contrast, photophysiology and pigments were less variable within each symbiont type from $P$. lutea indicating that niche acclimatization was rather regulated by a flexible association with a variable Symbiodinium community. Based on these data, we advocate an extended concept of phenotypic plasticity of the coral holobiont, in which the scleractinian host either associates with a specific Symbiodinium type with a broad physiological tolerance, or the host-symbiont pairing is more flexible to accommodate for different symbiont associations, each adapted to specific environmental settings.
\end{abstract}

KEY WORDS: Phenotypic plasticity - Symbiodinium - Symbiosis · Acclimatization - Coral reef · Red Sea $\cdot$ Pocillopora verrucosa $\cdot$ Porites lutea

\section{INTRODUCTION}

Hermatypic corals live in obligate symbioses with photosynthetic dinoflagellate endosymbionts from the genus Symbiodinium. Together, the coral host and algal symbionts are adapted to live under warm and oligotrophic conditions of tropical and subtropical oceans and constitute the foundation of coral

\footnotetext{
*Corresponding author: christian.voolstra@kaust.edu.sa
}

reefs, which are among the most productive and diverse marine ecosystems (Connell 1978).

Corals differ in their ability to adjust to varying environmental settings. For instance, some corals are able to acclimatize to a large range of light conditions, which results in a broad light and/or depth distribution. Flexible coral species can alter coral colony growth form (Einbinder et al. 2009) or production of

() The authors 2015. Open Access under Creative Commons by Attribution Licence. Use, distribution and reproduction are unrestricted. Authors and original publication must be credited. 
photoprotective compounds (Dunlap \& Shick 1998, Salih et al. 2000) to influence the internal light regime. In Symbiodinium, the ratio and composition of light-harvesting pigments, such as chl $a$, chlorophyll $C_{2}$ ( $\left.\mathrm{chl} C_{2}\right)$, and peridinin (peri), can be modulated to optimize size and number of photosynthetic units per symbiont cell (Iglesias-Prieto \& Trench 1994, 1997, Hennige et al. 2009). The adjustment of photopigments is often accompanied by a change in Symbiodinium cell densities (Frade et al. 2008). Further, the photoprotective pigments diadinoxanthin (Ddx) and diatoxanthin (Dtx) dissipate excess light energy through the de-epoxidation of Ddx to Dtx (Brown et al. 1999) and together with $\beta$-carotene ( $\beta$-car) they aid in the stabilization of the photosystem (PS) structure under light stress (Frank \& Cogdell 1996). Consequently, with increasing light, Symbiodinium harbor more photoprotective pigments in relation to light-harvesting pigments (Hennige et al. 2009).

Light acclimatization mechanisms increase photosynthetic efficiency (Lesser et al. 2010), which can be assessed for photosystem II (PSII) using pulseamplitude-modulated (PAM) fluorometry in situ (Ralph et al. 1999). Symbiodinium acclimatized to low light intensities feature low maximum electron transport rates $\left(\mathrm{ETR}_{\max }\right)$ and minimum saturating irradiances $\left(E_{\mathrm{k}}\right)$, while light use efficiency $(\alpha)$ and effective quantum yields $\left(\Delta F / F_{\mathrm{m}}{ }^{\prime}\right)$ are increased (Ralph \& Gademann 2005, Frade et al. 2008, Lesser et al. 2010). As natural light levels increase, Symbiodinium have increased ETR $\mathrm{max}_{\text {ax }}$ and $E_{\mathrm{k}}$, while $\alpha$ and $\Delta F / F_{\mathrm{m}}{ }^{\prime}$ follow an opposite trend (Ralph \& Gademann 2005).

Genetically distinct Symbiodinium types or species differ in their photophysiological properties and acclimatization capacity (Chang et al. 1983, IglesiasPrieto \& Trench 1997, Hennige et al. 2009). Consequently, acclimatization mechanisms of so-called generalist coral species include changes of the Symbiodinium community composition along environmental gradients (Baker 2003). For example, it has been shown that some corals associate with different Symbiodinium types along depth gradients (Rowan \& Knowlton 1995), which may confer a functional advantage to the coral host (Cooper et al. 2011). Furthermore, host-Symbiodinium associations may vary in response to a range of environmental factors at different spatio-temporal scales. In several coral species in the Great Barrier Reef, the prevalence of Symbiodinium from clade $\mathrm{C}$ at offshore locations converge to the prevalence of Symbiodinium from clade D with increasing coastal influence (Ulstrup \& van Oppen 2003). Comparable changes of Symbiodinium communities in response to season are less common
(Chen et al. 2005); studies that monitored several coral species over $5 \mathrm{yr}$ demonstrated that most hostSymbiodinium combinations are stable over time (Thornhill et al. 2006), although background shuffling (McGinley et al. 2012), and shifting dominance between co-occurring types within the same Symbiodinium community does occur (Ulstrup et al. 2008). Taken together, flexible association with Symbiodinium types along environmental gradients is an important factor that broadens a coral's distribution range (Rodriguez-Lanetty et al. 2001, Bongaerts et al. 2010). Conversely, inflexible host-Symbiodinium associations, for example, as seen in Pavona gigantea and Pocillopora verrucosa in the Gulf of California, may be limiting a species' depth distribution (IglesiasPrieto et al. 2004) and render it more vulnerable to environmental change (Buddemeier \& Fautin 1993, Berkelmans \& van Oppen 2006).

In the central Red Sea, water temperatures undergo large variation and regularly exceed $32^{\circ} \mathrm{C}$ in the summer (Davis et al. 2011), but little is known about how corals acclimatize to the differences in prevailing environmental conditions. In this study, we assessed whether compensation mechanisms differ between coral species harboring a specific Symbiodinium type and corals that are known to associate with a variable Symbiodinium community to further understand the interaction between host-Symbiodinium specificity and acclimatization potential of the coral holobiont. To address this knowledge gap, we investigated acclimatization mechanisms in 2 dominant central Red Sea corals, P. verrucosa and Porites lutea, on a spatio-temporal scale that incorporated nearshore vs offshore and seasonal variability. In particular, we were interested in the dynamics of the coral-associated Symbiodinium community in relation to photophysiology and pigment composition to identify drivers of seasonal niche acclimatization in this understudied coral reef ecosystem.

\section{MATERIALS AND METHODS}

\section{Study location}

The study was conducted in the central Saudi Arabian Red Sea along a cross-shelf and depth gradient. Four colonies of $P$. verrucosa and P. lutea were sampled at $1,5,10$, and $20 \mathrm{~m}$ each at a nearshore reef, 'Inner Fsar' $\left(22^{\circ} 13.974^{\prime} \mathrm{N}, 39^{\circ} 01.784^{\prime} \mathrm{E}\right)$, a midshore reef, 'Al Fahal' $\left(22^{\circ} 15.100^{\prime} \mathrm{N}, 38^{\circ} 57.386^{\prime} \mathrm{E}\right)$, and an offshore reef, 'Shib Nazar' $\left(22^{\circ} 21.006^{\prime} \mathrm{N}\right.$, $\left.38^{\circ} 51.139^{\prime} \mathrm{E}\right)$, located 3,10 , and $25 \mathrm{~km}$ from the 
shore, respectively. Sampling took place in February and September 2012, during the coldest and hottest months of the year, respectively. As a consequence of a previous bleaching event (Furby et al. 2013), P. verrucosa colonies were absent at shallow depths of the nearshore location in February and 2 extra samples from 10 and $20 \mathrm{~m}$ were taken. In September we were able to sample re-grown colonies, resulting in a total of 87 samples from $P$. verrucosa and 96 samples from P. lutea.

\section{Environmental parameters}

Three CTD (SBE 16plusV2, Seabird Electronics) casts were performed per site and season around noon recording data on photosynthetic active radiation (PAR), water temperature, salinity, oxygen saturation, and turbidity. Discrete water samples were taken at the coral sampling depths with $10 \mathrm{l}$ Niskin bottles and analyzed for total suspended matter (TSM), carbon and nitrogen concentrations of TSM and their isotopic ratios reported as \%o $\delta^{13} \mathrm{C}$ and \%o $\delta^{15} \mathrm{~N}$ relative to Pee Dee Belemnite standard and atmospheric nitrogen, respectively, as well as chlorophyll content, silicate, and inorganic nutrients (i.e. ammonia, nitrate and nitrite, phosphate) following procedures outlined in Ziegler et al. (2014).

\section{In situ photophysiology}

On the sampling days between 09:00 and 10:00 h the light-adapted state of PSII of the coral-associated symbionts was assessed with PAM fluorometry (Ralph et al. 1999). Three effective quantum yields $\left(\Delta F / F_{\mathrm{m}}{ }^{\prime}\right)$ and one rapid light curve (RLC) were measured with a Diving PAM (Walz) at 4 positions across the upper, non-shaded part of the colony for $P$. verrucosa (light steps: 106, 176, 271, 435, 560, 769, 1069, $1558 \mu \mathrm{mol}$ photons $\mathrm{m}^{-2} \mathrm{~s}^{-1}$ ) and $P$. lutea (light steps: 90, 175, 244, 348, 437, 620, 819, $1215 \mu \mathrm{mol}$ photons $\mathrm{m}^{-2} \mathrm{~s}^{-1}$ ). The following RLC parameters were calculated using linear regression: minimum saturating irradiance $\left(E_{\mathrm{k}}\right)$ and maximum light utilization coefficient $(\alpha)$. Maximum electron transport rate $\left(E R_{\max }\right)$ was calculated using the formula: ETR $=$ PAR $\times$ $\left(\Delta F / F_{\mathrm{m}}{ }^{\prime}\right) \times 0.5 \times A$ (Genty et al. 1989), where $A=\mathrm{ab}$ sorptance (calculated as $A=1$ - reflectance). Reflectance was measured as the fraction of light between 400 to $750 \mathrm{~nm}$ reflected by the coral surface following Enriquez et al. (2005) using a Ramses-ACC-VIS spectrophotometer (TriOS).

\section{Sample processing}

After in situ measurements, a small piece of each colony was collected, rinsed with filtered seawater, and snap-frozen in liquid nitrogen. Coral tissue was removed from the snap-frozen skeletons using an airbrush, slurry and symbiont aliquots were separated by centrifugation and washed according to Ziegler et al. (2014). Paraffin wax dipping was used to measure the surface areas of the bleached skeletons (Veal et al. 2010).

Symbiodinium cell densities were determined with 6 replicate counts in a Neubauer-improved haemocytometer in a light microscope and calculated per coral surface area. Symbiont pigments were extracted from disrupted cells in $90 \%$ methanol with $1 \mathrm{mM}$ Tris and separated on a Chromolith 18C reverse-phase HPLC column (Merck) and quantified as detailed in Ziegler et al. (2014). The ratio of light-harvesting pigments ( $\mathrm{chl} a_{1}, \mathrm{chl} c_{2}$, peri) to photoprotective pigments ( $\beta$-car, $\mathrm{Ddx}, \mathrm{Dtx})$, and the xanthophyll de-epoxidation $\left(\operatorname{Dtx} \times[\operatorname{Dtx}+\operatorname{Ddx}]^{-1}\right)$ were calculated.

Proteins were extracted by incubation of coral tissue in $0.5 \mathrm{M} \mathrm{NaOH}$ for $30 \mathrm{~min}$ at $90^{\circ} \mathrm{C}$. The protein content was measured according to Lowry et al. (1951) against a bovine serum albumin standard (DC protein assay, Bio-Rad).

\section{Symbiodinium identification via ITS2-DGGE and ITS2 sequencing}

DNA extraction and PCR amplification of the Symbiodinium ITS2 region were conducted according to Ziegler et al. (2014). Briefly, DNA was extracted using Chelex resin (100-200 mesh, Sigma). For the PCR, the forward primer 'ITS2intfor' and the reverse primer 'ITS2CLAMP' that contains a GC clamp were used (LaJeunesse \& Trench 2000). Denaturing gradient gel electrophoresis (DGGE) was conducted to separate the PCR products for $16 \mathrm{~h}$ at $150 \mathrm{~V}$ and $60^{\circ} \mathrm{C}$ on an $8 \%$ polyacrylamide gel with a $45-80 \%$ urea-formamide gradient (LaJeunesse 2002). Denaturing gels were stained with SYBR Safe (Invitrogen), photographed, dominant bands were excised, and subsequent re-amplification and sequencing were conducted as detailed in Ziegler et al. (2014). The ITS2 sequences were edited and aligned with Geneious 4.8.4 and BLASTed against GenBank 'nr' database for ITS2 type designation and verification of DGGE fingerprints. 


\section{Statistical analyses}

Maximum likelihood Chi-square tests were performed to examine significant differences in the distribution of Symbiodinium types across seasons, sites, and depths using the software Statistica 9.1. Permutational multivariate analyses of variance (PERMANOVA) were conducted on overall physiology and for each physiological variable separately to test for significant differences between coral species. Subsequently, we tested for differences in the factors site, season, and the co-variate sampling depth (all fixed) on environmental and coral physiology variables in each species separately. The PERMANOVA routine was run using 9999 permutations with sequential sum of squares and permutation of residuals under a reduced model with post-hoc pairwise comparisons. Multivariate patterns of physiological variables were visualized using non-metric multidimensional scaling (nMDS). Data were $\log (x+1)$ transformed and Euclidean distances computed prior to analyses.

To identify combinations of abiotic water parameters that best explained the multivariate physiological pattern of the coral samples, a biological-environmental matching routine (BioENV) was computed with 99 permutations on Spearman rank correlations between environmental and physiological resemblance matrices. Input data were normalized prior to analysis. All multivariate analyses were run using PRIMER v6 software (Clarke \& Gorley 2006).

\section{RESULTS}

To understand the relationship between environmental variability and acclimatization mechanisms in a coral host-symbiont framework, we measured 16 environmental (see Fig. S1, Table S1 in the Supplement at www.int-res.com/articles/suppl/m533p149_ supp.pdf) and 14 physiological parameters in the corals Pocillopora verrucosa (Fig. S2, Table S2) and Porites lutea (Fig. S3, Table S3) over 2 sampling times, across 3 sites, and 4 depths.

\section{Coral-Symbiodinium associations}

Symbiodinium microadriaticum (i.e. type A1) was the prevalent symbiont species in $P$. verrucosa (found in 80 of 87 colonies) across the shelf gradient and over seasons. Symbiodinium type A21 (GenBank accession number [ACN]: KF939534), which was recently reported from $P$. verrucosa in the southern Red Sea (Sawall et al. 2014), was found in 4 colonies at the nearshore site (site 3, Fig. 1A). At the offshore site, C15 was observed in a single colony. Two other colonies harbored a novel Symbiodinium type designated as C98 (ACN: KJ882303). In contrast, Symbiodinium associations of $P$. lutea, were highly plastic and dependent on variable factors such as cross-shelf gradient, depth, and season (Fig. 1A, Fig. 2D). Different Symbiodinium types belonging to clade C were prevalent offshore and midshore, while $40 \%$ (i.e. 13 of 32 colonies) of nearshore $P$. lutea colonies hosted Symbiodinium type D1a (Chi-square test; $\mathrm{p}<$ 0.005) (Fig. 1). Furthermore, there was a significant depth interaction, with 31 of 32 colonies bearing type C15 symbionts limited to deep (10 and $20 \mathrm{~m})$ water (Chi-square test; $\mathrm{p}<0.001$ ). In the shallow waters (1 and $5 \mathrm{~m}$ ), novel C15 variants: C15n (ACN: KJ882299), C15o (ACN: KJ882300), C15p (ACN: KJ882301), and 2 novel types of C97 (ACN: KJ882302) and C99 (ACN: KJ882304), were prevalent instead. Moreover, there was a significant trend from $\mathrm{C} 15 \mathrm{n}$ dominance in winter to $\mathrm{C} 15 \mathrm{p}$ in summer (Chi-square test; $\mathrm{p}<0.05$ ).

\section{Environmental patterns}

The study sites were subjected to strong seasonal fluctuation, as indicated by more than half of the environmental variables displaying significant differences between winter and summer (Table 1, see Fig. S1 and Table S1 in the Supplement). Water temperature, light intensity, and to a lesser degree, salinity were all significantly higher in summer than in winter (Table 1, Fig. 3A). In contrast, several factors indicating an increase in ecosystem productivity related to nutrient enrichment were increased in winter; these included turbidity, chlorophyll, oxygen saturation, silicate, and phosphate, while $\delta^{13} \mathrm{C}$ decreased during winter (Table 1, see Fig. S1, Table S1, and 'Supplemental results' in the Supplement).

Despite the overall oligotrophic conditions in the central Red Sea, we detected a significant gradient of inorganic nutrients, phytoplankton, turbidity, and stable isotopic signature of the suspended matter across sites. In summer, environmental conditions at the offshore site were significantly different from midshore and nearshore sites (pairwise PERMANOVA $_{i} \mathrm{p}<0.005$ and $\mathrm{p}<0.001$, respectively) that were not significantly different from each other $(\mathrm{p}>$ 0.05). By comparison, in winter the nearshore site was significantly different from midshore and off- 

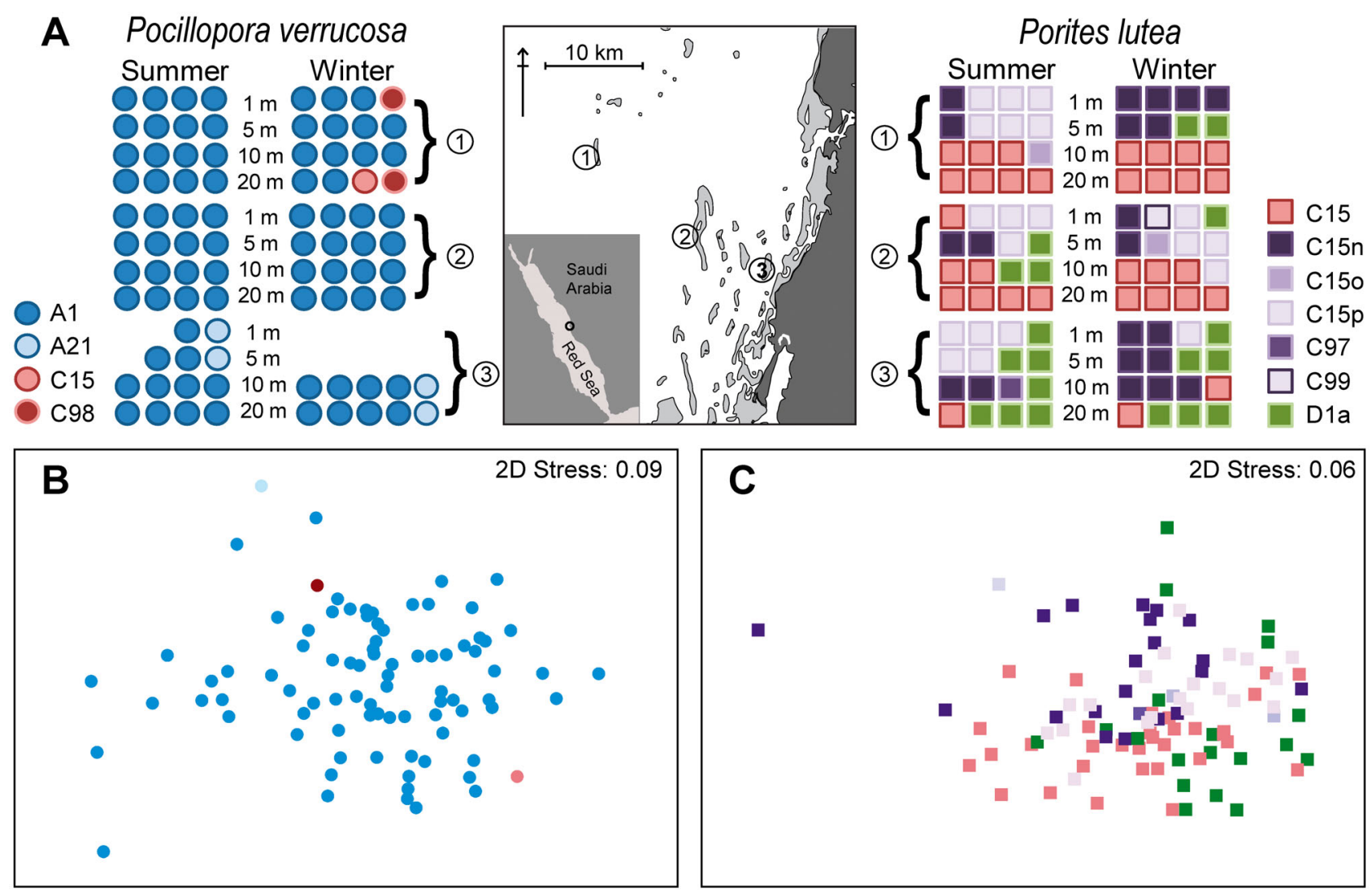

Fig. 1. Symbiodinium composition and physiology in colonies of Pocillopora verrucosa and Porites lutea in the central Red Sea. (A) Symbiodinium types across coral samples collected from 3 cross-shelf locations $(1=$ offshore, $2=$ midshore, and $3=$ nearshore) and 4 depths $(1,5,10$, and $20 \mathrm{~m}$ ) in the central Red Sea during summer and winter of 2012. (B,C) Non-metric multidimensional scaling (nMDS) ordination plots of 14 physiological variables measured from samples of (B) P. verrucosa and (C) P. lutea. Each symbol represents a sample (see panel A for color codes)

shore sites (pairwise PERMANOVA; $\mathrm{p}<0.005$ and $\mathrm{p}<0.001$, respectively), which in turn were not significantly different from each other $(\mathrm{p}>0.05)$. Overall, 6 of 16 variables correlated with water depth, resulting in overall significant differences between depths (PERMANOVA $;$ p < 0.001) (Fig. 3A, Table 1, see 'Supplemental results' in the Supplement). Based on PERMANOVA pseudo- $F$ values for the factors season, site, and depth, 2-dimensional plots were generated as a comparative tool to visualize the weight of the separate variables with respect to these factors (Fig. 3).

\section{Patterns in photophysiology}

Seasonal niche acclimatization operated differently in both coral species (Fig. 2A). During winter, ETR $_{\max }$ and $E_{\mathrm{k}}$ of Symbiodinium cells in $P$. verrucosa were around 1.5 times higher than for those associated with P. lutea. In summer, ETR $\mathrm{max}_{\max }$ and $E_{\mathrm{k}}$ signifi- cantly increased in $P$. verrcuosa symbionts while they decreased in those of $P$. lutea (Table 2, Figs. S2 \& S3, Tables S2 \& S3), thereby more than doubling the differences in these variables between both species (Fig. 2B). Other important factors contributing to the seasonal pattern in both species were apparent from chlorophyll fluorescence data, in particular, an increased effective quantum yield of PSII $\left(\Delta F / F_{\mathrm{m}}{ }^{\prime}\right)$, and a significant decrease in light use efficiency $(\alpha)$ were observed during winter (Table 2). Furthermore, photophysiology was affected along the cross-shelf gradient in $P$. verrucosa symbionts (Fig. $3 C$ ). $E_{\mathrm{k}}$ at the offshore site was significantly increased compared to the nearshore site in winter (pairwise PERMANOVA; $p<0.005)$, and compared to midshore $(p<0.01)$ and nearshore $(p<0.05)$ sites in summer. Light use efficiency $\alpha$, the only parameter that differed between sites in summer, was stable in winter. During summer, $\alpha$ at the offshore site was significantly lower than at midshore (pairwise PERMANOVA $; \mathrm{p}<0.005$ ) and nearshore $(p<0.05)$. Photophysiological acclima- 

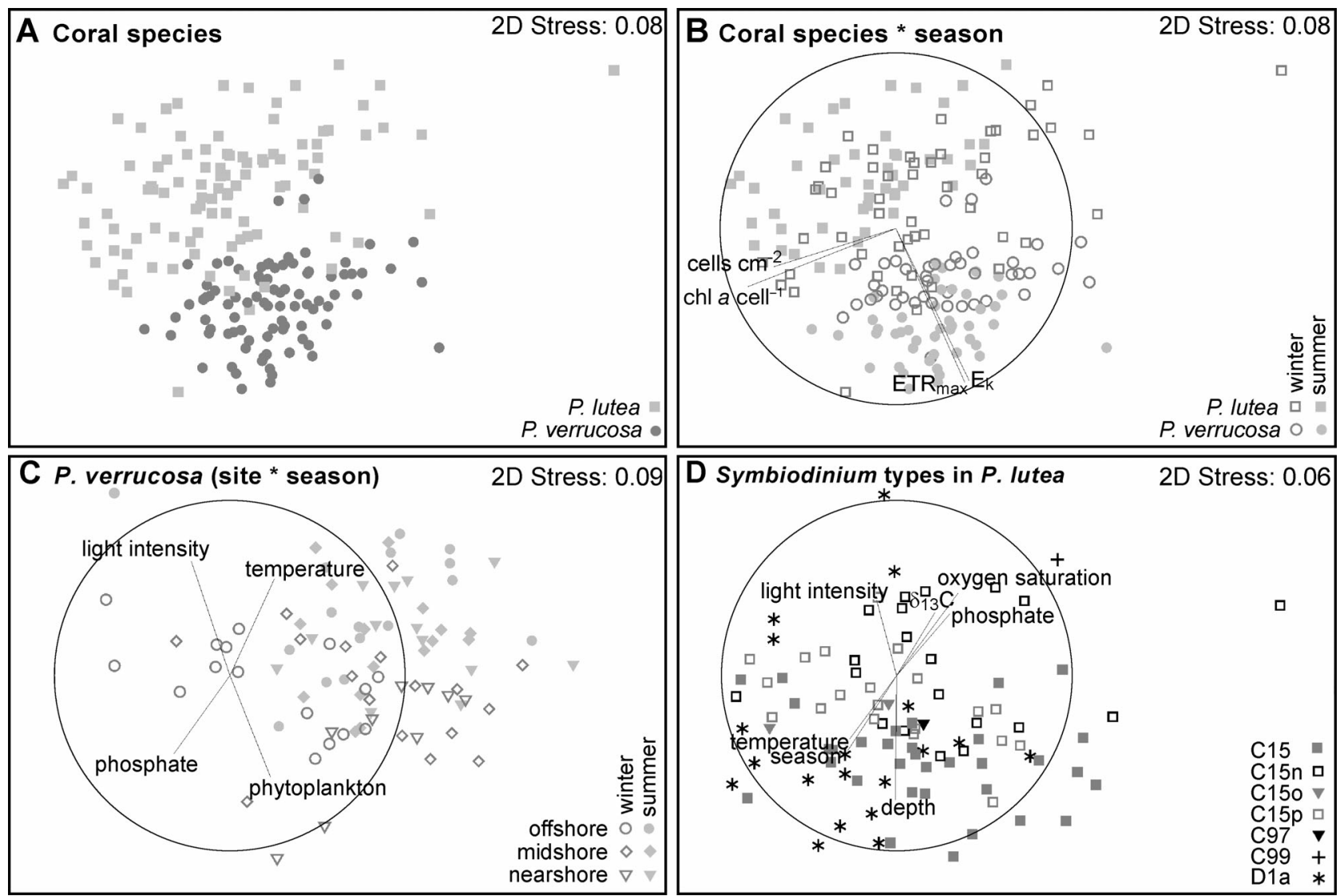

Fig. 2. Non-metric multidimensional scaling (nMDS) ordination plots of physiological parameters in Porites lutea and Pocillopora verrucosa corals in the central Red Sea; measured in (A) $P$. lutea and $P$. verrucosa, (B) $P$. lutea and $P$. verrucosa during winter and summer seasons, (C) in $P$. verrucosa during winter and summer across 3 cross-shelf locations (nearshore, midshore, offshore) and (D) in relation to Symbiodinium types in P. lutea. Vector overlays (representing multiple regression correlations) indicate environmental factors contributing most to the separation of data

Table 1. PERMANOVA test results for 16 abiotic variables measured from water samples and CTD casts $(\mathrm{n}=72)$ in the central Red Sea. Analyses are displayed for the factors season (winter and summer), site (nearshore, midshore, offshore), and depth (1, 5,10 , and $20 \mathrm{~m}$ ). Test results for all variables combined (first row) and variables analyzed separately are shown. TSM = total suspended matter. Significant differences $(\mathrm{p}<0.05)$ are shown in bold, ns = not significant

\begin{tabular}{|c|c|c|c|c|c|c|}
\hline \multirow[t]{2}{*}{ Variable } & \multicolumn{2}{|c|}{ Effect of season } & \multicolumn{2}{|c|}{ Effect of site(season) } & \multicolumn{2}{|c|}{ Effect of covariate: depth } \\
\hline & Pseudo- $F$ & $\mathrm{p}($ perm) & Pseudo- $F$ & $\mathrm{p}($ perm) & Pseudo- $F$ & $\mathrm{p}($ perm $)$ \\
\hline All variables & 17.81 & 0.0001 & 5.24 & 0.0001 & 71.93 & 0.0001 \\
\hline Temperature $\left({ }^{\circ} \mathrm{C}\right)$ & 1663.3 & 0.0001 & 3.99 & 0.0072 & 21.17 & 0.0001 \\
\hline Light intensity ( $\mu \mathrm{mol}$ photons $\mathrm{m}^{-2} \mathrm{~s}^{-1}$ ) & 37.48 & 0.0001 & 4.84 & 0.0019 & 218.12 & 0.0001 \\
\hline $\mathrm{O}_{2}$ saturation $(\%)$ & 178.17 & 0.0001 & 6.58 & 0.0001 & 7.93 & 0.0052 \\
\hline Silicate $\left(\mu \mathrm{mol} \mathrm{l}^{-1}\right)$ & 64.48 & 0.0001 & 7.87 & 0.0002 & 8.28 & 0.0046 \\
\hline Chl a $\left(\mu \mathrm{g} \mathrm{l}^{-1}\right)$ & 33.44 & 0.0001 & 7.31 & 0.0002 & 4.10 & 0.0445 \\
\hline$\delta^{13} \mathrm{C}$ of TSM & 228.83 & 0.0001 & 13.17 & 0.0001 & 1.48 & $\mathrm{~ns}$ \\
\hline Turbidity (NTU) & 29.96 & 0.0001 & 18.62 & 0.0001 & 2.35 & ns \\
\hline Salinity (PSU) & 9.34 & 0.0035 & 4.02 & 0.0060 & 0.59 & ns \\
\hline Phosphate $\left(\mu \mathrm{mol} \mathrm{l^{-1 }}\right)$ & 144.56 & 0.0001 & 0.72 & ns & 0.66 & ns \\
\hline$\%$ C of TSM & 2.43 & $\mathrm{~ns}$ & 11.41 & 0.0001 & 2.76 & ns \\
\hline$\% \mathrm{~N}$ of $\mathrm{TSM}$ & 1.10 & ns & 9.07 & 0.0001 & 2.51 & $\mathrm{~ns}$ \\
\hline $\mathrm{C}: \mathrm{N}$ of $\mathrm{TSM}$ & 0.02 & ns & 3.14 & 0.0197 & 0.98 & ns \\
\hline Nitrite + nitrate $\left(\mu \mathrm{mol} \mathrm{l}{ }^{-1}\right)$ & 0.08 & ns & 2.42 & ns & 4.09 & 0.0474 \\
\hline Ammonia $\left(\mu \mathrm{mol} \mathrm{l} \mathrm{l}^{-1}\right)$ & 0.11 & ns & 0.53 & ns & 2.67 & $\mathrm{~ns}$ \\
\hline$\delta^{15} \mathrm{~N}$ of TSM & 0.61 & ns & 1.73 & ns & 0.39 & ns \\
\hline $\mathrm{TSM}\left(\mathrm{mg} \mathrm{l}^{-1}\right)$ & 2.01 & ns & 0.35 & $\mathrm{~ns}$ & 0.09 & ns \\
\hline
\end{tabular}




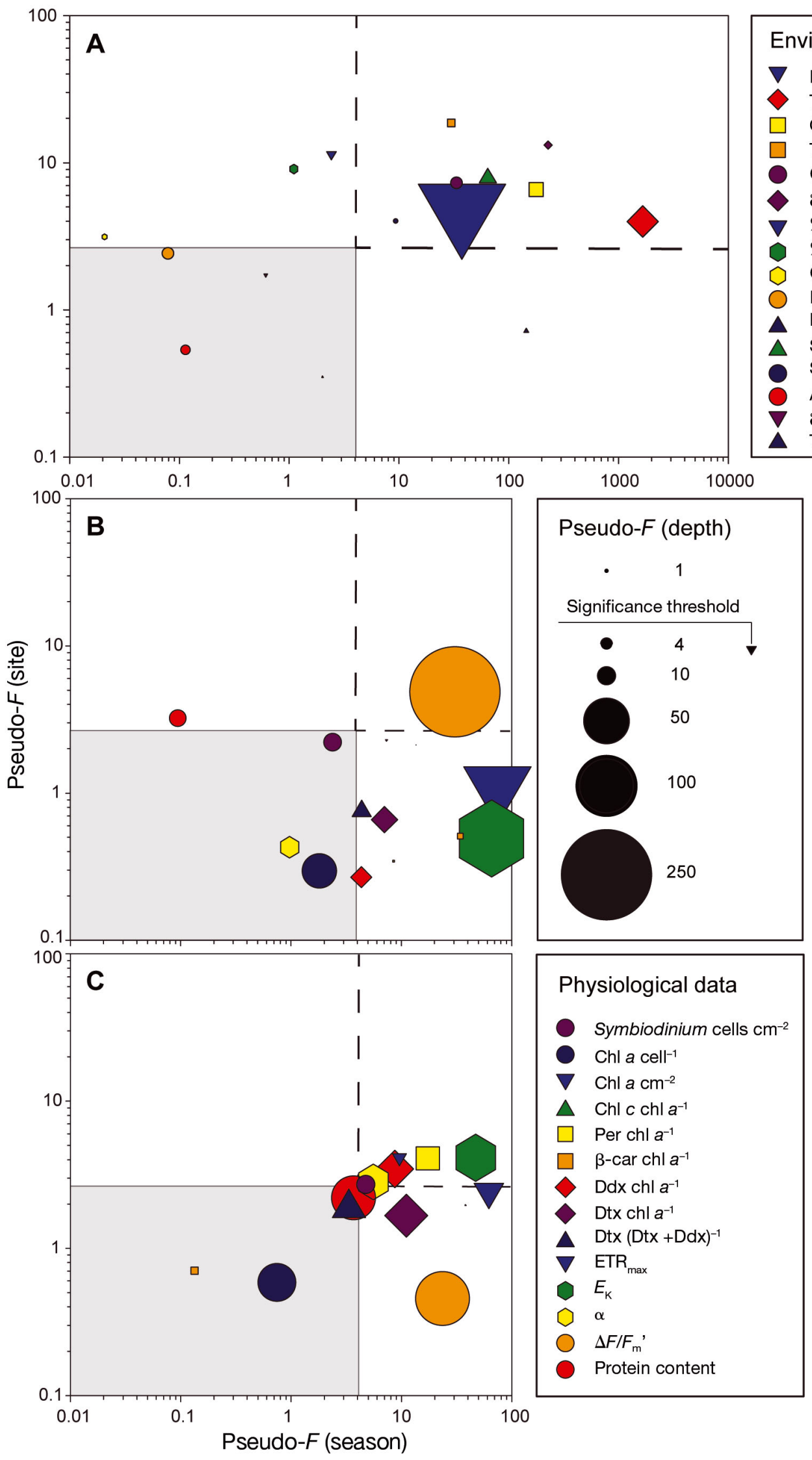

Fig. 3. Univariate PERMANOVA pseudo- $F$ plots of (A) environmental data, and (B) physiological variables of Porites lutea and (C) Pocillopora verrucosa in the central Red Sea. Pseudo- $F$ values of the factors season (winter, summer) and site (nearshore, midshore, offshore) are represented on $x$ - and $y$-axes, respectively. Vertical and horizontal lines mark the values above which pseudo- $F$ values were significant; data points in the grey boxes were not significant for either factor. Larger symbol sizes represent stronger contribution (i.e. higher pseudo- $F$ values) of the factor depth $(1,5,10$, and $20 \mathrm{~m})$, with the significance threshold marked in the key. Keys show symbols representing environmental variables in panel $\mathrm{A}$, and physiological variables measured in coral species $P$. lutea, and $P$. verrucosa in panels $\mathrm{B}$ and $\mathrm{C}$, respectively 


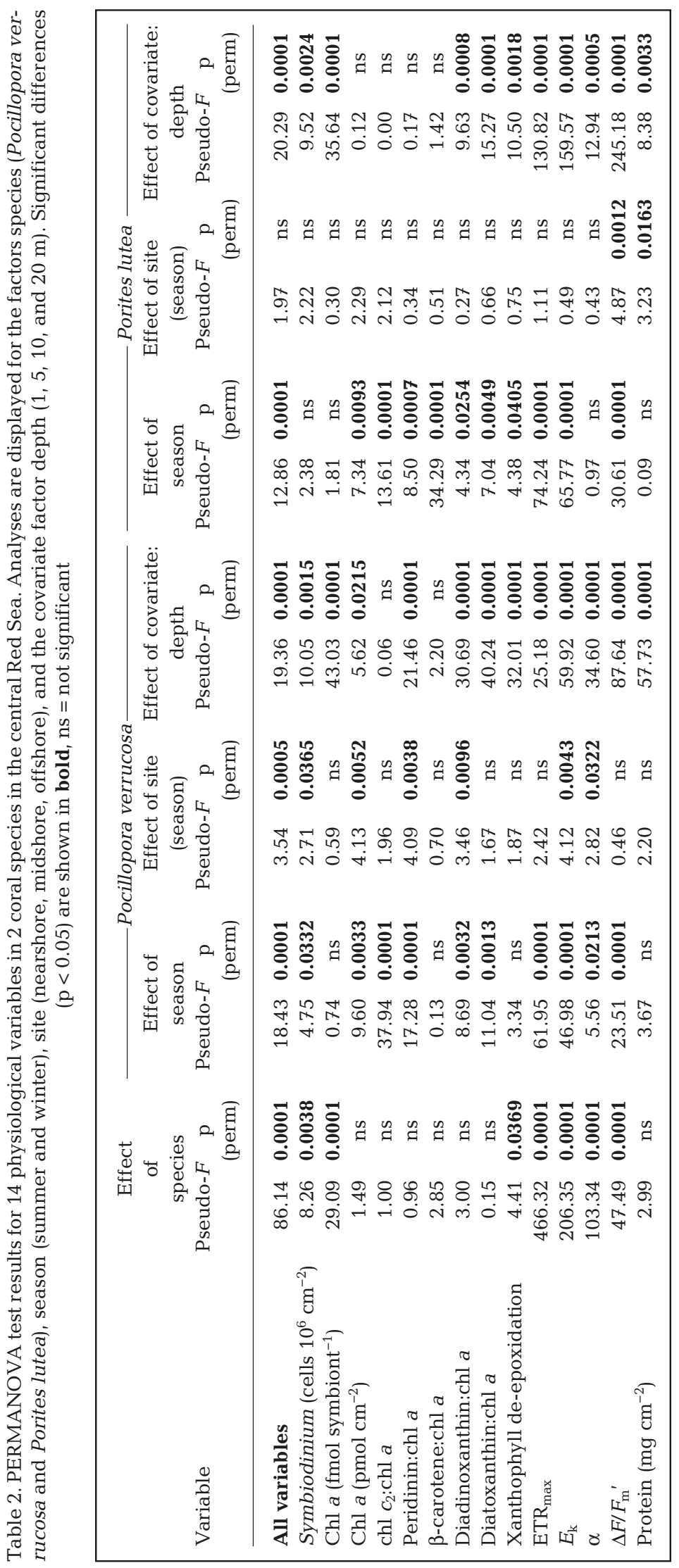

tization operated most strongly along the depth gradient in both species (Fig. 3B,C). $\mathrm{ETR}_{\max }$ and $E_{\mathrm{k}}$ significantly decreased between 1 and $20 \mathrm{~m}$ in symbionts of $P$. verrucosa and $P$. lutea. While the maximum electron transport rate decreased with depth, light use efficiency $(\alpha)$ and effective quantum yield of PSII $\left(\Delta F / F_{\mathrm{m}}{ }^{\prime}\right)$ significantly increased in both species (Table 2).

\section{Patterns in photosynthetic pigments}

Seasonality of the photosynthetic pigment composition varied between species. In $P$. lutea, Dtx:chl $a$, peri:chl a ratios, and xanthophyll de-epoxidation were significantly increased during winter, while $\mathrm{chl} \mathrm{C}_{2}$ : $\mathrm{chl} a$ and $\beta$-car:chl a ratios were significantly decreased at the same time (Table 2 ). In $P$. verrucosa, peri:chl $a$ and chl $c_{2}$ :chl a ratios behaved similar to $P$. lutea, while Dtx:chl $a_{\text {, }}$ $\beta$-car:chl $a$, and xanthophyll de-epoxidation remained stable (Table 2). Both species displayed increases in symbiont densities and cellular chlorophyll content, leading to significantly increased areal chlorophyll concentrations in summer (24-31\%) (Table 2). In addition, in $P$. verrucosa there was also a cross-shelf response during winter with reduced Symbiodinium cell densities at the offshore site compared to the midshore site (pairwise PERMANOVA; $\mathrm{p}<0.001$ ) with no significant difference to the nearshore site $(p>0.05)$. As a consequence, areal chlorophyll concentrations were reduced at the offshore site during winter, compared to the midshore (pairwise PERMANOVA; $\mathrm{p}<$ $0.001)$ and nearshore site $(p<0.05)$. Site differences in winter also affected the pigment composition; while peri:chl a ratio decreased with distance to shore, Ddx:chl a increased (pairwise PERMANOVA $;$ p < 0.05). In summer, Ddx:chl a ratios at the offshore site decreased to levels similar to those found in the midshore site ( $p>0.05)$, whilst the nearshore site was stable between seasons and significantly lower than the midshore site $(\mathrm{p}<$ 0.005).

General mechanisms of depth acclimatization, as assessed by differences in photosynthetic pigments, operated similarly in both species. For example, proportions of photo- 
protective pigments of the xanthophyll cycle decreased with depth in relation to chl $a$. In $P$. verrucosa, Ddx and Dtx decreased 48 and $60 \%$, respectively, from 1 to $20 \mathrm{~m}$ depth (Fig. S2, Table S2). In $P$. lutea, Ddx and Dtx decreased by 25 and $57 \%$ respectively, from 1 to $20 \mathrm{~m}$ depth (Fig. S3, Table S3). Concomitantly, xanthophyll de-epoxidation rates decreased from 1 to $20 \mathrm{~m}$ in both species, while $\beta$-car, the third photoprotective pigment, was stable across depth. The main light-harvesting pigment $\mathrm{chl} a$ showed a reversed trend to the photoprotective pigments. Chl a in Symbiodinium cells increased from 1 to $20 \mathrm{~m}$ in both species. Whilst chl a almost doubled in $P$. verrucosa, increases in $P$. lutea were smaller. Symbiodinium cell densities followed an opposite trend to cellular chl a and decreased with depth. Despite reduced Symbiodinium densities in deeper water, cellular increases in chl $a$ in $P$. verrucosa resulted in significantly increased areal chl a concentrations at $20 \mathrm{~m}$ compared to $1 \mathrm{~m}$. In P. lutea, areal chl $a$ did not change with depth and the composition of other light-harvesting components such as chl $C_{2}$ and peri were also stable between 1 and $20 \mathrm{~m}$. In $P$. verrucosa, chl $c_{2}: \mathrm{chl}$ a ratio was stable, while peri:chl $a$ ratio decreased from 1 to $20 \mathrm{~m}$.

Finally, protein content was not significantly different between seasons for both corals (Table 2, Figs. S2 \& S3, Tables S2 \& S3). Protein content decreased with depth (between 1 and $20 \mathrm{~m}$ ) by $42 \%$ in $P$. verrucosa and by $32 \%$ in P. lutea.

\section{Link between environmental and physiological patterns in relation to host-symbiont specificity}

A biological-environmental matching routine (BioENV in PRIMER) revealed that environmental parameters strongly correlated with a structuring of physiology in $P$. verrucosa. Light intensity and turbidity, together with $\delta^{13} \mathrm{C}(\mathrm{r}=0.520)$ or temperature $(\mathrm{r}=0.516)$, best explained the multivariate physiological pattern in $P$. verrucosa. By comparison, for $P$. lutea, the best explanatory variables were light intensity, oxygen saturation $(r=0.214)$, combined with turbidity $(r=0.212)$, and light intensity and temperature $(r=0.204)$, but the structuring was less stringent. The significant correlation of environmental gradients with the physiology of $P$. verrucosa was apparent between sampling times, cross-shelf locations, and depths (Fig. 2C, Table 2). Interestingly, the physiological signature was not significantly different between sites during summer (pairwise PERMANOVA $_{i} p>0.05$ ), whilst in winter there were signif- icant differences in physiology at the offshore site compared to the midshore $(p<0.001)$ and nearshore site $(p<0.01)$, which were not significantly different from each other $(p>0.05)$. Overall, physiology in $P$. lutea was less variable and not significantly different along the cross-shelf gradient, whilst significant differences between sampling times and depths were of approximately equal importance (Table 2). Taking these results together with the differences in Symbiodinium association, the correlation of environmental gradients with physiology observed in $P$. lutea can be related to distinct physiological properties of the different Symbiodinium types over sites, sampling times, and depths (Fig. 1C). In contrast, in $P$. verrucosa the single dominant species $S$. microadriaticum was responsible for the observed large physiological plasticity (Fig. 1B).

\section{DISCUSSION}

Our analyses of coral acclimatization mechanisms over time and across sites and depths in a comparative coral host-symbiont framework in the Red Sea revealed that strategic differences between Pocillopora verrucosa (with high symbiont specificity) and Porites lutea (with high symbiont flexibility) exist, which affect their phenotypic plasticity.

\section{Differences in coral-Symbiodinium specificity}

The coral host's reproductive mode and symbiont acquisition strategy can have an effect on host-symbiont specificity (LaJeunesse et al. 2004, Stat et al. 2008). Here, both investigated coral species pass on endosymbionts to their offspring (Kojis \& Quinn 1981, Kinzie 1993), and despite these similar reproductive strategies, $P$. verrucosa and $P$. lutea had different patterns in the host-symbiont specificity. Most colonies of $P$. verrucosa showed a prevalent association with $S$. microadriaticum as has previously been described for this species in the central Red Sea (Sawall et al. 2014, Ziegler et al. 2014). In contrast, Symbiodinium association of $P$. lutea was variable and correlated with spatio-temporal factors such as cross-shelf gradient, depth, and sampling time. The conversion from corals associated with Symbiodinium from clade $\mathrm{C}$ to those with clade $\mathrm{D}$ with decreasing distance to shore corresponds to reports of Acropora valida and Acropora millepora in the Great Barrier Reef (Ulstrup \& van Oppen 2003). In this regard, our findings contribute to the perception of 
symbionts from clade D as conferring tolerance towards unfavourable environmental settings on their respective hosts (Berkelmans \& van Oppen 2006).

In accordance with our findings, depth stratification of the host-symbiont relationship is common in coral species maintaining variable associations with Symbiodinium (Rowan \& Knowlton 1995). However, the observed shift between sampling points from dominance of Symbiodinium C15n in winter to C15p in summer was unexpected. Whilst seasonality of Symbiodinium communities has been observed before in Acropora palifera (Chen et al. 2005), most corals exhibit stable Symbiodinium associations over time (Thornhill et al. 2006, McGinley et al. 2012). However, this seasonality effect was limited to shallow water, where environmental variability was highest, which has previously been proposed as an explanation for more heterogeneous Symbiodinium communities at shallow sites relative to deep sites (Thornhill et al. 2006).

Generally, the flexibility in the association of $P$. lutea with diverse Symbiodinium types is remarkable. Despite its high bleaching tolerance, it was assumed that Porites had a strict association with Symbidinium type C3 in the Persian Gulf (Hume et al. 2013) and with type C15 in the Pacific (Franklin et al. 2012), although Symbiodinium from clade G have recently been encountered in background abundances in some colonies of Porites lobata in Hawaii (Stat et al. 2013). Contrasting the assumption of $P$. lutea as a symbiont specialist, we found diversity in its association with different novel Symbiodinium ITS2 types, suggesting a potential alternative mechanism conferring plasticity along environmental gradients in the Red Sea.

\section{Acclimatization mechanisms and differences between coral species}

The photosynthetic properties of $P$. verrucosa identified this species as adapted to high light conditions. For instance, compared to P. lutea, $\Delta F / F_{\mathrm{m}}{ }^{\prime}, \mathrm{ETR}_{\max }$ and $E_{\mathrm{k}}$ were higher in $P$. verrucosa, and in response to the combined effects of increased light intensities and temperature, and decreased turbidity during summer, ETR max $_{\text {ax }}$ and $E_{\mathrm{k}}$ were both increased in $P$. verrucosa. The same mechanism of increasing $E_{\mathrm{k}}$ and decreasing $\alpha$ was also apparent in $P$. verrucosa with increasing distance to shore, similar to sun-adapted surfaces of $P$. damicornis and A. valida that had higher $\mathrm{ETR}_{\max }$ and $E_{\mathrm{k}}$ compared to shade-adapted surfaces of the same colony (Ulstrup et al. 2008).
Furthermore, Symbiodinium cell densities in $P$. verrucosa increased in summer and hence were positively correlated with temperature and light. This increase is contrary to decreasing Symbiodinium cell densities in other species during summer (Fagoonee et al. 1999, Fitt et al. 2000) and further corroborates to the notion that $P$. verrucosa constitutes a well acclimatized species to prevailing environmental conditions. In contrast, decreased $\mathrm{ETR}_{\max }$ and $E_{\mathrm{k}}$ in P. lutea during summer conform to photoprotective processes in the symbionts (Jones \& Hoegh-Guldberg 2001, Warner et al. 2002), such as non-photochemical quenching, a key mechanism in all photosynthetic eukaryotes, including Symbiodinium spp. (Reynolds et al. 2008), to dissipate excess energy as heat through xanthophyll cycling (Li et al. 2009). However, at the same time xanthophyll cycling did not show a clear pattern and thus non-photochemical quenching alone cannot account for the decrease in $\mathrm{ETR}_{\max }$. This is consistent with observations across a $60 \mathrm{~m}$ depth gradient (Ziegler et al. 2015) and may indicate limited plasticity of photoprotective xanthophyll conversion in this species (Warner \& Berry-Lowe 2006), but additional data are needed, e.g. at higher temporal resolution, to draw further conclusions. In addition, near the water surface where light intensities were highest, $\Delta F / F_{\mathrm{m}}$ ' of symbionts in $P$. lutea was reduced to levels that are symptomatic of photoinhibition (Brown et al. 1999, Jones \& Hoegh-Guldberg 2001). As expected, xanthophyll cycling measured for both coral species increased in shallow water allowing more photoprotection in these brighter environments. On average xanthophyll cycling was higher in $P$. verrucosa than in $P$. lutea symbionts, again demonstrating the stronger acclimatization of the former to the prevailing environmental conditions. Moreover, this species-specific difference in photoprotective activity extends previous findings by Ulstrup et al. (2008) who found higher photoprotective cycling of xanthophylls in symbionts associated with $P$. damicornis compared to those of $A$. valida.

Seasonality of chl a content in Symbiodinium cells or of areal chl $a$, mediated by changing cell densities, is a common phenomenon in corals (Fagoonee et al. 1999, Fitt et al. 2000). In contrast, reports of seasonal changes of photopigment composition or stoichiometric ratios have been rare, while they are more commonly known from the well-studied depth-mediated light gradients (Kaiser et al. 1993, Lesser et al. 2010). In this study, light harvesting pigment concentrations per symbiont cell more than doubled in $P$. verrucosa and increased $50 \%$ in P. lutea from 1 to $20 \mathrm{~m}$ depth, and seasonal photophysiology of $P$. verrucosa and 
$P$. lutea was also accompanied by changes in photopigment composition. For instance, during summer peri:chl a ratios decreased, while $\mathrm{chl} \mathrm{C}_{2}$ :chl a ratios increased, indicating functional changes in the photosynthetic units as have previously been found in cultures of S. microadriaticum (Iglesias-Prieto \& Trench 1997) and other Symbiodinium types (Hennige et al. 2009). In P. verrucosa, enrichment of peri:chl $a$ and Ddx:chl a ratios further accompanied photophysiological acclimatization along the cross-shelf gradient, suggesting that this process was driven by enrichment of light-harvesting complexes (Hofmann et al. 1996, Niedzwiedzki et al. 2014). Corresponding to the exponential change in light intensity, photophysiological alterations were more pronounced across depths, than between sites, or sampling times. However, despite the apparent connection between depth-mediated light differences and photosynthetic properties, it is important to consider that changes in light intensity do not occur in isolation and that light is only one of several environmental factors interacting with photoacclimatization. For instance, photosynthetic pigment composition was more strongly influenced by seasonal variation than by the depth gradient, signifying a central role of several environmental factors such as temperature, turbidity, and oxygen saturation in shaping the photosynthetic apparatus.

\section{Environmental patterns and physiological plasticity in relation to host-symbiont specificity}

The magnitude and pattern of the physiological response to the environmental gradients was different between coral species and dependent on the flexibility of their association with different Symbiodinium types. Photophysiological changes in the prevalent species $S$. microadriaticum found in $P$. verrucosa were significant across depths, while they were comparably smaller within each of $P$. lutea's changing Symbiodinium types. In addition to depth-mediated changes in irradiance, several environmental factors were related to ecosystem productivity, and correlated with changes in physiology along the cross-shelf gradient in $P$. verrucosa and its stable community of $S$. microadriaticum (as elucidated by the BioENV analysis). In response to gradients of phytoplankton, turbidity, stable isotopic signature of the suspended matter, and temperature between sites during winter, photophysiological changes in symbionts of $P$. verrucosa followed some typical acclimatization mechanisms, such as increased effective quantum yields and decreased minimum satu- rating irradiances (Cooper \& Ulstrup 2009). In accordance with a decrease of environmental differences, these correlations became less obvious in summer. Conversely, physiology remained stable in $P$. lutea (i.e. only 2 of the 14 variables were different across the shelf for this species compared to 6 variables in $P$. verrucosa), while its Symbiodinium community changed along the cross-shelf gradient. Other studies reported comparably small physiological acclimatization for P. lutea, e.g. along a gradient of anthropogenic impact in China (Roder et al. 2013) or in an area impacted by large amplitude internal waves in Thailand (Roder et al. 2011). However, Symbiodinium identity was not determined in these studies and it remains uncertain as to whether the here-proposed mechanism of symbiont flexibility in P. lutea can be generalized. Overall, coral populations along reefs in the Red Sea seem to be connected (Robitzch et al. 2015), but host genotypic divergence may have played a role in the observed host-symbiont pattern in P. lutea as has been shown for Seriatopora hystrix in the Great Barrier Reef (Bongaerts et al. 2010).

\section{CONCLUSION}

In this study, we observed diverging acclimatization mechanisms over time, cross-shelf locations, and depths in $P$. verrucosa and $P$. lutea. While $P$. verrucosa was predominantly associated with $S$. microadriaticum and showed strong physiological response to changing environmental conditions, a highly plastic Symbiodinium community in P. lutea was associated with distinct physiologies and only minor physiological acclimatization. Based on these data, we advocate an extended concept of phenotypic plasticity towards environmental variability as a consequence of the flexibility in the host-Symbiodinium association. Symbiont specialist host corals can associate with a specific Symbiodinium type with a high physiological tolerance, allowing for high acclimatization potential of the coral holobiont to a range of environmental conditions, and hence compensating the inflexibility in the host-Symbiodinium relationship. This is in contrast to coral species with highly variable Symbiodinium communities, where differential association of symbionts adapted to specific environmental settings provides an alternative mechanism of acclimatization. Moreover, our findings challenge previous assumptions of presumed host-symbiont specificity in $P$. lutea, and emphasize the notion that specificity might largely depend on the investigated time scale, environmental space, and sampling effort. 
To date, the interactions between environment, coral host, Symbiodinium community, and photosynthetic properties are not fully understood. In light of environmental change, it is essential to gain further insights into the complex interplay of these parameters.

Acknowledgements. We thank KAUST CMOR staff and T. Sinclair-Taylor for their assistance, the Bioscience Core Lab at KAUST for sequencing, W. Krämer for advice on absorptance measurements, M. Messer for statistical guidance, and the anonymous reviewers and the editor whose comments guided us in improving the manuscript. Research reported in this publication was supported by the King Abdullah University of Science and Technology (KAUST). MZ was financially supported by 'LOEWE' funding scheme of Hesse's Ministry of Higher Education, Research, and the Arts and a DAAD postgraduate travel grant.

\section{LITERATURE CITED}

Baker AC (2003) Flexibility and specificity in coral-algal symbiosis: diversity, ecology, and biogeography of Symbiodinium. Annu Rev Ecol Evol Syst 34:661-689

- Berkelmans R, van Oppen MJH (2006) The role of zooxanthellae in the thermal tolerance of corals: a 'nugget of hope' for coral reefs in an era of climate change. Proc $\mathrm{R}$ Soc B 273:2305-2312

Bongaerts P, Riginos C, Ridgway T, Sampayo EM and others (2010) Genetic divergence across habitats in the widespread coral Seriatopora hystrix and its associated Symbiodinium. PLoS ONE 5:e10871

Brown BE, Ambarsari I, Warner ME, Fitt WK, Dunne RP, Gibb SW, Cummings DG (1999) Diurnal changes in photochemical efficiency and xanthophyll concentrations in shallow water reef corals: evidence for photoinhibition and photoprotection. Coral Reefs 18:99-105

Buddemeier RW, Fautin DG (1993) Coral bleaching as an adaptive mechanism - a testable hypothesis. Bioscience 43:320-326

Chang SS, Prézelin BB, Trench RK (1983) Mechanisms of photoadaptation in three strains of the symbiotic dinoflagellate Symbiodinium microadriaticum. Mar Biol 76: 219-229

> Chen CA, Wang JT, Fang LS, Yang YW (2005) Fluctuating algal symbiont communities in Acropora palifera (Scleractinia: Acroporidae) from Taiwan. Mar Ecol Prog Ser 295:113-121

Clarke K, Gorley R (2006) PRIMER v6: user manual/tutorial. PRIMER-E, Plymouth

Connell JH (1978) Diversity in tropical rain forests and coral reefs. Science 199:1302-1310

Cooper TF, Ulstrup KE (2009) Mesoscale variation in the photophysiology of the reef building coral Pocillopora damicornis along an environmental gradient. Estuar Coast Shelf Sci 83:186-196

Cooper TF, Ulstrup KE, Dandan SS, Heyward AJ and others (2011) Niche specialization of reef-building corals in the mesophotic zone: metabolic trade-offs between divergent Symbiodinium types. Proc R Soc B 278:1840-1850

Davis KA, Lentz SJ, Pineda J, Farrar JT, Starczak VR, Churchill JH (2011) Observations of the thermal environment on Red Sea platform reefs: a heat budget analysis. Coral Reefs 30:25-36
Dunlap WC, Shick JM (1998) Ultraviolet radiation-absorbing mycosporine-like amino acids in coral reef organisms: a biochemical and environmental perspective. J Phycol 34:418-430

> Einbinder S, Mass T, Brokovich E, Dubinsky Z, Erez J, Tchernov D (2009) Changes in morphology and diet of the coral Stylophora pistillata along a depth gradient. Mar Ecol Prog Ser 381:167-174

> Enriquez S, Mendez ER, Iglesias-Prieto R (2005) Multiple scattering on coral skeletons enhances light absorption by symbiotic algae. Limnol Oceanogr 50:1025-1032

> Fagoonee I, Wilson HB, Hassell MP, Turner JR (1999) The dynamics of zooxanthellae populations: a long-term study in the field. Science 283:843-845

> Fitt WK, McFarland FK, Warner ME, Chilcoat GC (2000) Seasonal patterns in tissue biomass and densities of symbiotic dinoflagellates in reef corals and relation to coral bleaching. Limnol Oceanogr 45:677-685

> Frade PR, Bongaerts P, Winkelhagen AJS, Tonk L, Bak RPM (2008) In situ photobiology of corals over large depth ranges: a multivariate analysis on the roles of environment, host, and algal symbiont. Limnol Oceanogr 53: 2711-2723

Frank HA, Cogdell RJ (1996) Carotenoids in photosynthesis. Photochem Photobiol 63:257-264

Franklin EC, Stat M, Pochon X, Putnam H, Gates R (2012) GeoSymbio: a hybrid, cloud-based web application of global geospatial bioinformatics and ecoinformatics for Symbiodinium-host symbioses. Mol Ecol Resour 12: 369-373

Furby KA, Bouwmeester J, Berumen ML (2013) Susceptibility of central Red Sea corals during a major bleaching event. Coral Reefs 32:505-513

Genty B, Briantais JM, Baker NR (1989) The relationship between the quantum yield of photosynthetic electron transport and quenching of chlorophyll fluorescence. Biochim Biophys Acta 990:87-92

> Hennige SJ, Suggett DJ, Warner ME, McDougall KE, Smith DJ (2009) Photobiology of Symbiodinium revisited: biophysical and bio-optical signatures. Coral Reefs 28: 179-195

Hofmann E, Wrench PM, Sharples FP, Hiller RG, Welte W, Diederichs K (1996) Structural basis of light harvesting by carotenoids: peridinin-chlorophyll-protein from Amphidinium carterae. Science 272:1788-1791

Hume B, D'Angelo C, Burt J, Baker AC, Riegl B, Wiedenmann J (2013) Corals from the Persian/Arabian Gulf as models for thermotolerant reef-builders: Prevalence of clade C3 Symbiodinium, host fluorescence and ex situ temperature tolerance. Mar Pollut Bull 72:313-322

> Iglesias-Prieto R, Trench RK (1994) Acclimation and adaptation to irradiance in symbiotic dinoflagellates. I. Responses of the photosynthetic unit to changes in photon flux density. Mar Ecol Prog Ser 113:163-175

Iglesias-Prieto R, Trench RK (1997) Acclimation and adaptation to irradiance in symbiotic dinoflagellates. II. Response of chlorophyll-protein complexes to different photon flux densities. Mar Biol 130:23-33

Iglesias-Prieto R, Beltran VH, LaJeunesse TC, Reyes-Bonilla $H$, Thome PE (2004) Different algal symbionts explain the vertical distribution of dominant reef corals in the eastern Pacific. Proc R Soc B 271:1757-1763

> Jones RJ, Hoegh-Guldberg O (2001) Diurnal changes in the photochemical efficiency of the symbiotic dinoflagellates (Dinophyceae) of corals: photoprotection, photoinactiva- 
tion and the relationship to coral bleaching. Plant Cell Environ 24:89-99

Kaiser P, Schlichter D, Fricke HW (1993) Influence of light on algal symbionts of the deep water coral Leptoseris fragilis. Mar Biol 117:45-52

Kinzie RA (1993) Spawning in the reef corals Pocillopora verrucosa and $P$. eydouxi at Sesoko Island, Okinawa. Galaxea 11:93-105

Kojis BL Quinn NJ (1981) Reproductive startegies in four species of Porites (Scleractinia). Proc 4th Int Coral Reef Symp, Manila 2:145-151

$>$ LaJeunesse TC (2002) Diversity and community structure of symbiotic dinoflagellates from Caribbean coral reefs. Mar Biol 141:387-400

> LaJeunesse TC, Trench RK (2000) Biogeography of two species of Symbiodinium (Freudenthal) inhabiting the intertidal sea anemone Anthopleura elegantissima (Brandt). Biol Bull 199:126-134

LaJeunesse TC, Bhagooli R, Hidaka M, DeVantier L and others (2004) Closely related Symbiodinium spp. differ in relative dominance in coral reef host communities across environmental, latitudinal and biogeographic gradients. Mar Ecol Prog Ser 284:147-161

Lesser MP, Slattery M, Stat M, Ojimi M, Gates RD, Grottoli A (2010) Photoacclimatization by the coral Montastraea cavernosa in the mesophotic zone: light, food, and genetics. Ecology 91:990-1003

Li Z, Wakao S, Fischer BB, Niyogi KK (2009) Sensing and responding to excess light. Annu Rev Plant Biol 60:239-260

> Lowry OH, Rosebrough N, Farr A, Randall R (1951) Protein measurement with the Folin phenol reagent. J Biol Chem 193:265-275

> McGinley MP, Aschaffenburg MD, Pettay DT, Smith RT, LaJeunesse TC, Warner ME (2012) Symbiodinium spp. in colonies of eastern Pacific Pocillopora spp. are highly stable despite the prevalence of low-abundance background populations. Mar Ecol Prog Ser 462:1-7

> Niedzwiedzki DM, Jiang J, Lo CS, Blankenship RE (2014) Spectroscopic properties of the chlorophyll a-chlorophyll $c_{2}$-peridinin-protein-complex (acpPC) from the coral symbiotic dinoflagellate Symbiodinium. Photosynth Res 120:125-139

Ralph PJ, Gademann R (2005) Rapid light curves: a powerful tool to assess photosynthetic activity. Aquat Bot 82: 222-237

> Ralph PJ, Gademann R, Larkum AWD, Schreiber U (1999) In situ underwater measurements of photosynthetic activity of coral zooxanthellae and other reef dwelling dinoflagelate endosymbionts. Mar Ecol Prog Ser 180:139-147

Reynolds JM, Bruns BU, Fitt WK, Schmidt GW (2008) Enhanced photoprotection pathways in symbiotic dinoflagellates of shallow-water corals and other cnidarians. Proc Natl Acad Sci USA 105:13674-13678

Robitzch V, Banguera-Hinestroza E, Sawall Y, Al-Sofyani A, Voolstra CR (2015) Absence of genetic differentiation in the coral Pocillopora verrucosa along environmental gradients of the Saudi Arabian Red Sea. Front Mar Sci 2:5

Roder C, Jantzen C, Schmidt GM, Kattner G, Phongsuwan N, Richter C (2011) Metabolic plasticity of the corals Porites lutea and Diploastrea heliopora exposed to large amplitude internal waves. Coral Reefs 30:57-69
Roder C, Wu ZJ, Richter C, Zhang J (2013) Coral reef degradation and metabolic performance of the scleractinian coral Porites lutea under anthropogenic impact along the NE coast of Hainan Island, South China Sea. Cont Shelf Res 57:123-131

Rodriguez-Lanetty M, Loh W, Carter D, Hoegh-Guldberg O (2001) Latitudinal variability in symbiont specificity within the widespread scleractinian coral Plesiastrea versipora. Mar Biol 138:1175-1181

Rowan R, Knowlton N (1995) Intraspecific diversity and ecological zonation in coral algal symbiosis. Proc Natl Acad Sci USA 92:2850-2853

Salih A, Larkum A, Cox G, Kuhl M, Hoegh-Guldberg O (2000) Fluorescent pigments in corals are photoprotective. Nature 408:850-853

Sawall Y, Al-Sofyani A, Banguera-Hinestroza E, Voolstra CR (2014) Spatio-temporal analyses of Symbiodinium physiology of the coral Pocillopora verrucosa along large-scale nutrient and temperature gradients in the Red Sea. PLoS ONE 9:e103179

Stat M, Loh WKW, Hoegh-Guldberg O, Carter DA (2008) Symbiont acquisition strategy drives host-symbiont associations in the southern Great Barrier Reef. Coral Reefs 27:763-772

Stat M, Pochon X, Franklin EC, Bruno JF, Casey KS, Selig ER, Gates RD (2013) The distribution of the thermally tolerant symbiont lineage (Symbiodinium clade D) in corals from Hawaii: correlations with host and the history of ocean thermal stress. Ecol Evol 3:1317-1329

Thornhill DJ, LaJeunesse TC, Kemp DW, Fitt WK, Schmidt GW (2006) Multi-year, seasonal genotypic surveys of coral-algal symbioses reveal prevalent stability or postbleaching reversion. Mar Biol 148:711-722

Ulstrup KE, van Oppen MJH (2003) Geographic and habitat partitioning of genetically distinct zooxanthellae (Symbiodinium) in Acropora corals on the Great Barrier Reef. Mol Ecol 12:3477-3484

Ulstrup KE, Hill R, van Oppen MJH, Larkum AWD, Ralph PJ (2008) Seasonal variation in the photo-physiology of homogeneous and heterogeneous Symbiodinium consortia in two scleractinian corals. Mar Ecol Prog Ser 361: $139-150$

- Veal CJ, Carmi M, Fine M, Hoegh-Guldberg O (2010) Increasing the accuracy of surface area estimation using single wax dipping of coral fragments. Coral Reefs 29: 893-897

Warner ME, Berry-Lowe S (2006) Differential xanthophyll cycling and photochemical activity in symbiotic dinoflagellates in multiple locations of three species of Caribbean coral. J Exp Mar Biol Ecol 339:86-95

- Warner ME, Chilcoat GC, McFarland FK, Fitt WK (2002) Seasonal fluctuations in the photosynthetic capacity of photosystem II in symbiotic dinoflagellates in the Caribbean reef-building coral Montastraea. Mar Biol 141: 31-38

Ziegler M, Roder C, Büchel C, Voolstra C (2014) Limits to physiological plasticity of the coral Pocillopora verrucosa from the central Red Sea. Coral Reefs 33:1115-1129

Ziegler M, Roder C, Büchel C, Voolstra C (2015) Mesophotic coral depth acclimatization is a function of host-specific symbiont physiology. Front Mar Sci 2:4 